\title{
Associations of anemia persistency with medical expenditures in Medicare ESRD patients on dialysis
}

This article was published in the following Dove Press journal:

Therapeutics and Clinical Risk Management

20 April 2009

Number of times this article has been viewed

Jiannong Liu'

Haifeng Guo'

David Gilbertson'

Robert Foley ${ }^{1,2}$

Allan Collins ${ }^{1,2}$

'Chronic Disease Research Group, Minneapolis Medical Research Foundation, Minneapolis, MN, USA; ${ }^{2}$ Department of Medicine, University of Minnesota, Minneapolis, MN, USA

Correspondence: Jiannong Liu Chronic Disease Research Group, Minneapolis Medical Research Foundation, 914 South 8th Street, Suite S-253, Minneapolis, MN 55404, USA

Tel + I 6I2 3477695

Fax+l 6123475878

Email jliu@cdrg.org
Abstract: Most end-stage renal disease (ESRD) patients begin renal replacement therapy with hemoglobin levels below the recommended US National Kidney Foundation Dialysis Outcomes Quality Initiative Guidelines lower level of $110 \mathrm{~g} / \mathrm{L}$. Although most patients eventually reach this target, the time required varies substantially. This study aimed to determine whether length of time with below-target hemoglobin levels after dialysis initiation is associated with medical costs, and if so, whether intermediate factors underlie the associations. US patients initiating dialysis in 2002 were studied using the Centers for Medicare and Medicaid Services ESRD database. Anemia persistence (time in months with hemoglobin below $110 \mathrm{~g} / \mathrm{L}$ ) was determined in a six-month entry period, and outcomes were assessed in the subsequent six-month follow-up period. The structural equation modeling technique was used to evaluate associations between persistent anemia and medical costs and to determine intermediate factors for these associations. The study included 28,985 patients. Mean per-patient-per-month medical cost was $\$ 6267$ (standard deviation \$5713) in the six-month follow-up period. Each additional month with hemoglobin below $110 \mathrm{~g} / \mathrm{L}$ was associated with an $8.9 \%$ increment in medical cost. The increased cost was associated with increased erythropoietin use and blood transfusions, and increased rates of hospitalization and vascular access procedures in the follow-up period.

Keywords: anemia persistency, end-stage renal disease, medical costs, structural equation modeling

\section{Introduction}

For dialysis patients in the United States, hemoglobin levels have increased yearly since erythropoietin-stimulating agents (ESA) were introduced into clinical practice in $1989 .{ }^{1}$ In early 1991, the mean hemoglobin level for end-stage renal disease (ESRD) patients was $96 \mathrm{~g} / \mathrm{L}$, and the level for $84.5 \%$ of patients was below the recommended National Kidney Foundation Dialysis Outcomes Quality Initiative (KDOQI) Guidelines lower target level of $110 \mathrm{~g} / \mathrm{L} .{ }^{2,3}$ By June 2005, the mean hemoglobin level had increased to $119 \mathrm{~g} / \mathrm{L}$ and levels were below $110 \mathrm{~g} / \mathrm{L}$ for only $19.4 \%$ of patients. ${ }^{1}$ In contrast to the temporal trends in the overall population, most incident patients begin dialysis treatment with hemoglobin levels below $110 \mathrm{~g} / \mathrm{L}$. In 2005, values were below $110 \mathrm{~g} / \mathrm{L}$ for $67.4 \%$ of incident patients at dialysis initiation, ${ }^{1}$ and the time required to reach the target level varies considerably. Low hemoglobin in ESRD patients is associated with increased mortality, morbidity, hospitalization, and medical costs; these associations are well documented. ${ }^{4-11}$ One study also shows that longer time required to reach the target hemoglobin level was associated with significantly higher risk of hospitalization and mortality. ${ }^{12}$ The present study was designed to address whether 
persistent anemia, measured by length of time after dialysis initiation with hemoglobin levels below $110 \mathrm{~g} / \mathrm{L}$, is associated with economic outcomes, and if so, whether intermediate factors, through which persistent anemia affects outcomes, underlie these associations?

\section{Methods}

\section{Study population}

This study includes 2002 incident US ESRD patients with hemodialysis as renal replacement therapy and Medicare as primary payer at day 91 after dialysis initiation. A six-month entry (baseline) period was defined from dialysis months 4-9. Months 1-3 were not used because data are incomplete for many patients. Patients who died, underwent transplant, changed primary payer, or whose hemoglobin was unreported or outside the range $33-183 \mathrm{~g} / \mathrm{L}$ in one or more months of the six-month entry period were excluded. Patients were followed from the first day after the entry period to the first of death, undergoing transplant, changing primary payer, or six months.

\section{Data sources and patient baselines}

Data used for this study came from the Centers for Medicare and Medicaid Services (CMS) Renal Management Information System (REMIS) and CMS Standard Analytical Files. The REMIS database includes information from the CMS Medicare Enrollment Database, the United Network for Organ Sharing transplant database, the ESRD Medical Evidence Report (form CMS-2728), and the ESRD Death Notification (form CMS-2746). The Standard Analytical Files include Medicare Part A institutional claims (inpatient, outpatient, skilled nursing, home health, and hospice) and Part B physician/supplier claims.

Patient baseline information included demographic characteristics, hospital days and hemoglobin levels in the entry period, and comorbid conditions. Demographic characteristics, including age, sex, race (white, African American, other), and ethnicity (Hispanic, non-Hispanic), were obtained from the REMIS database. Duration of hospital stays in the entry period was obtained from Part A inpatient claims in the Standard Analytical Files.

Comorbid conditions were characterized from Medicare Part A and Part B claims in the entry period, using International Classification of Diseases, Ninth Revision, Clinical Modification (ICD-9-CM) and Physicians' Current Procedural Terminology (CPT) codes (see Appendix for the specific codes). Conditions characterized were diabetes, atherosclerotic heart disease (ASHD), congestive heart failure
(CHF), peripheral vascular disease (PVD), cerebrovascular accident/transient ischemic attack (CVA/TIA), dysrhythmia, other cardiac diseases (including pericarditis, endocarditis, myocarditis, other complications of heart disease, heart transplant, heart valve replacement, and cardiac devices), cancer, liver disease, gastrointestinal bleeding, and chronic obstructive pulmonary disease (COPD). The method used for defining comorbid conditions from claims has been previously described. ${ }^{13}$

Patient hemoglobin values were obtained from the Medicare recombinant human erythropoietin (EPO) claims files derived from the outpatient Standard Analytical Files. For each patient, mean hemoglobin value was computed for each entry period month and for the entire entry period. The mean number of months with hemoglobin values below $110 \mathrm{~g} / \mathrm{L}$ in the entry period was calculated for the overall cohort. Anemia persistence was described by number of months with hemoglobin values below $110 \mathrm{~g} / \mathrm{L}$ in the entry period. To demonstrate the robustness of the analysis, we characterized persistent anemia in 2 additional ways: whether the number of months with hemoglobin level below $110 \mathrm{~g} / \mathrm{L}$ was higher than the overall cohort mean number of months, and mean hemoglobin level in the entry period.

\section{Outcomes}

In the follow-up period, total EPO dose, total number of blood transfusions, hospital days, and number of vascular access procedures were derived from Medicare Part A and Part B claims. Per-patient-per-month (PPPM) Medicare allowable costs were obtained from Medicare Part A and Part B claims. Institutional Medicare allowable costs include Medicare payment, coinsurance, deductibles, and any payment provided by a payer other than Medicare. Costs in the follow-up period were summed for each patient and divided by the number of follow-up months to obtain PPPM cost. ${ }^{10}$

\section{Statistical analysis}

Patient baseline characteristics were tabulated overall and by persistent anemia groups. Differences among groups were assessed using the chi-square test for categorical variables and the Wilcoxon rank sum test for continuous variables. Means and medians of EPO dose, number of blood transfusions, number of hospitalization days, and number of vascular access procedures in the follow-up period were also tabulated by persistent anemia group, and differences among groups were tested using the Wilcoxon rank sum test.

The structural equation modeling (SEM) technique was used to evaluate the associations between persistent anemia 
and medical costs and to assess the intermediate clinical factors underlying these associations. SEM is a combination of path analysis and factor analysis ${ }^{14,15}$ that has been widely used in the psychological, behavioral, and social sciences and was introduced to medical research recently. ${ }^{16-18}$ Because SEM allows several regression equations to be tested simultaneously, it characterizes both the overall association between independent and dependent variables and intermediate factors that describe the nature of the association.

Because SEM is most effective when data, especially endogenous (dependent) variables and latent variables (factors measured by one or more variables) indicators, are normally distributed, the continuous variables in our data were checked for normality and transformed if necessary. Instead of the original values for PPPM, EPO dose, and numbers of transfusions, hospitalization days, and vascular access procedures, the natural logarithm of PPPM expenditures and the square roots of EPO dose and numbers of blood transfusions, hospitalization days, and vascular access procedures were used in the models. Because outlier PPPM costs can cause severe skewness, patients whose costs were above the highest 0.25 th percentile or below the lowest 0.25 th percentile were excluded.

To reduce the number of variables in the analysis and the number of categorical variables in the model, a comorbidity score was used in the models to replace the binary comorbidity variables. To obtain the comorbidity score, a linear regression model was fit with logged PPPM as dependent variable and age, sex, race, ethnicity, number of months with hemoglobin values below $110 \mathrm{~g} / \mathrm{L}$, duration of hospitalizations in the entry period, and all individual comorbid conditions as independent variables. A weight was assigned to each comorbid condition associated with logged PPPM ( $p<0.05$ in the regression model). Weights were multiplied up relative to the smallest parameter estimate and in wholenumber increments. For example, the smallest parameter estimate for the significant comorbid conditions is 0.01642 for COPD, the parameter estimate for CHF is 0.0325 , and the parameter estimate for CVA is 0.04935; we assigned weight 1 to COPD, weight 2 to $\mathrm{CHF}$, and weight 3 to CVA. We assigned weight 1 to ASHD, COPD, and liver disease, 2 to $\mathrm{CHF}$ and other cardiovascular disease, 3 to CVA and PVD, and 4 to cancer. Gastrointestinal bleeding and dysrhythmia were nonsignificant. The comorbidity score for each patient was the sum of the weights based on the presence or absence of the comorbid conditions. In SEM, all relationships between endogenous variables and the corresponding exogenous variables should be linear. Plots and regression residual plots showed that the assumptions of linearity were met.
We hypothesized that the relationship between persistent anemia and total (all cause) medical cost was mediated by two factors: (1) anemia treatment and (2) general severity of illness. The anemia treatment factor was measured as EPO dose and number of blood transfusions in the follow-up period. The general severity of illness factor was measured by number of inpatient hospital days and number of vascular access procedures in the follow-up period. Mathematically, our assumed model is

$$
\begin{gathered}
Y=X_{1} \beta_{1}+X_{2} \beta_{2}+\varepsilon \\
X_{1}=X_{2} \gamma+\varepsilon_{1}
\end{gathered}
$$

where $Y$ is $\log (\mathrm{PPPM}) ; X_{1}$ includes anemia treatment (the common factor of EPO dose and number of transfusions in the follow-up period) and general severity of illness (the common factor of hospitalization days and number of vascular access procedures in the follow-up period); $X_{2}$ includes age, race, sex, ethnicity, number of hospital days in the entry period, comorbidity score and persistent anemia; $\varepsilon$ and $\varepsilon_{1}$ are residuals. A graphic expression of models (1) and (2) is displayed in Figure 1. For simplicity and clarity, all baseline variables except persistent anemia are grouped together, in a box labeled "Baseline variables." An arrow from one box to another, such as "Baseline variables" to "Medical costs," means that the baseline variables were hypothesized to affect medical costs in the follow-up period. To assess whether persistent anemia was associated with medical costs in ways other than those intermediated by anemia treatment and general severity of illness, persistent anemia was included in $X_{2}$ in regression model (1), representing the total of the direct and other indirect associations, if any, between persistent anemia and medical costs, other than associations intermediated by anemia treatment and general severity of illness.

\section{Results}

The study cohort comprised 28,985 incident patients. Figure 2 illustrates in detail the study exclusion criteria by which patients were selected. Mean number of months with hemoglobin values below the target value of $110 \mathrm{~g} / \mathrm{L}$ was 1.3 (Table 1). Persistent anemia groups were defined in three ways: number of months with hemoglobin values below $110 \mathrm{~g} / \mathrm{L}(0,1$ to 2 , or $\geq 3)$; whether the number of months with hemoglobin value below $110 \mathrm{~g} / \mathrm{L}$ was $\leq$ or $>1.3$, the cohort mean; and whether mean hemoglobin over the entry period was $<$ or $\geq 110 \mathrm{~g} / \mathrm{L}$. Younger age, female sex, African American race, Hispanic ethnicity, hospitalization during the entry period, and each comorbid condition studied were associated with persistent anemia. In the six-month follow-up period, mean follow-up time was 5.63 months per patient, and 


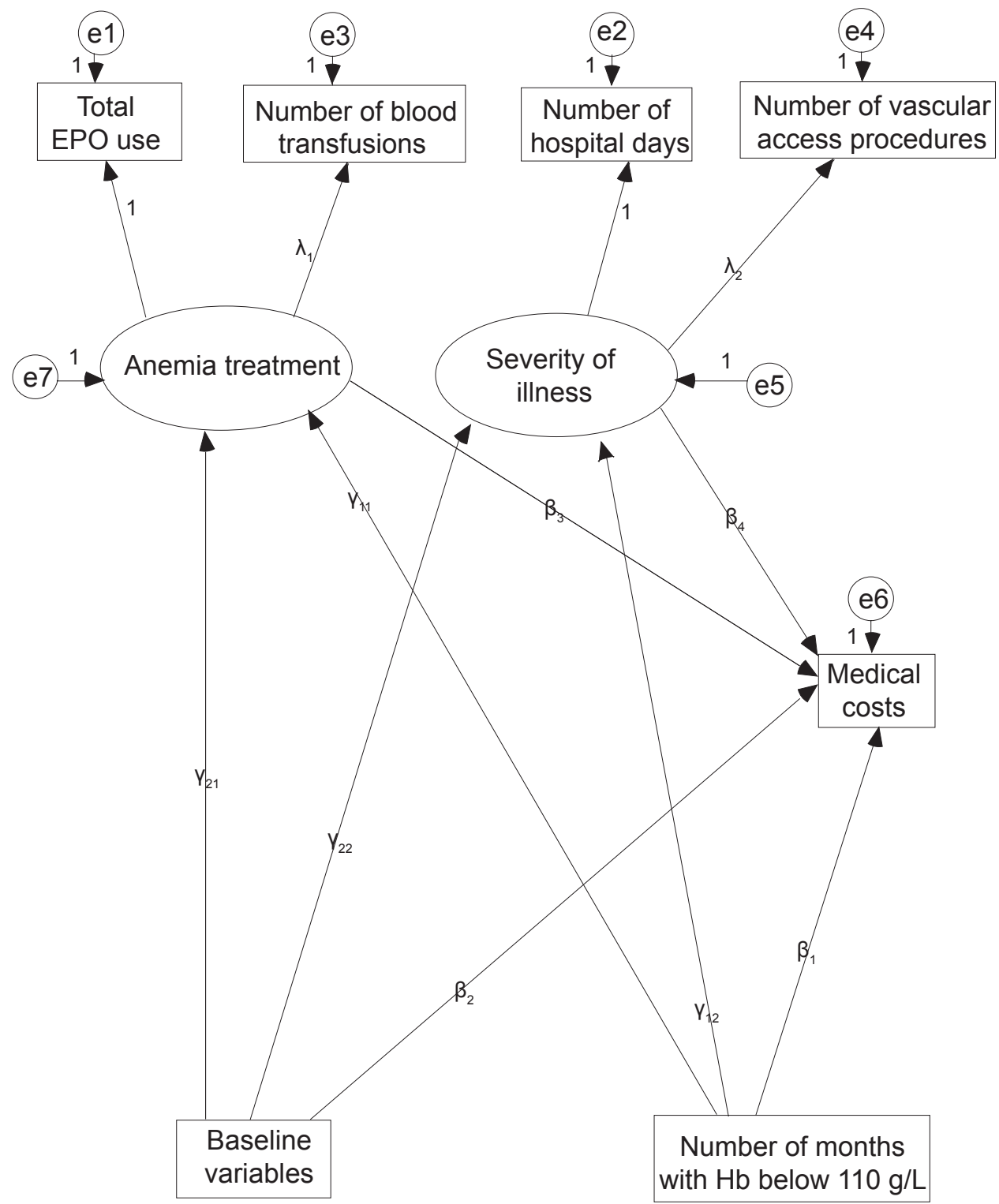

Figure I Graphical expression of assumed model. For simplicity and clarity, all baseline variables except persistent anemia appear together in a box labeled "Baseline variables." An arrow from one box to another, such as "Baseline variables" to "Medical costs," means that the baseline variables were hypothesized to affect medical costs in the follow-up period. The $e_{1}-e_{7}$ are residuals.

average medical cost was $\$ 6267$ per patient per month in the follow-up period.

Among persistent anemia groups, compared with the zero-month group, the one-to-two months group and $\geq$ three-months group had mean values that were $47.6 \%$ and $155.1 \%$ higher for EPO doses, $41.2 \%$ and $252.9 \%$ higher for number of blood transfusions, $26.9 \%$ and $98.4 \%$ higher for number of hospital days, and $16.2 \%$ and $39.1 \%$ higher for number of vascular access procedures, respectively, in the follow-up period (Table 2). The corresponding cost showed the same relationship with persistent anemia. Results were similar for the other anemia persistency measures.
Compared with PPPM cost for patients with zero months with hemoglobin level below $110 \mathrm{~g} / \mathrm{L}$, mean PPPM costs for patients with one to two months and $\geq$ three months below $110 \mathrm{~g} / \mathrm{L}$ were $14.9 \%$ and $47.8 \%$ higher, respectively (Table 3). The incremental costs were $29.3 \%$ higher for the $>1.3$-months group than for the $\leq 1.3$-months group, and $43.7 \%$ higher for the group with mean hemoglobin below $110 \mathrm{~g} / \mathrm{L}$ than for the group with mean hemoglobin above $110 \mathrm{~g} / \mathrm{L}$.

The $\beta_{1}$ in the structural equation model in Figure 1 was tested nonsignificant (the estimate is -0.006 and the $p$-value is 0.622 ). Thus, except for associations intermediated by 


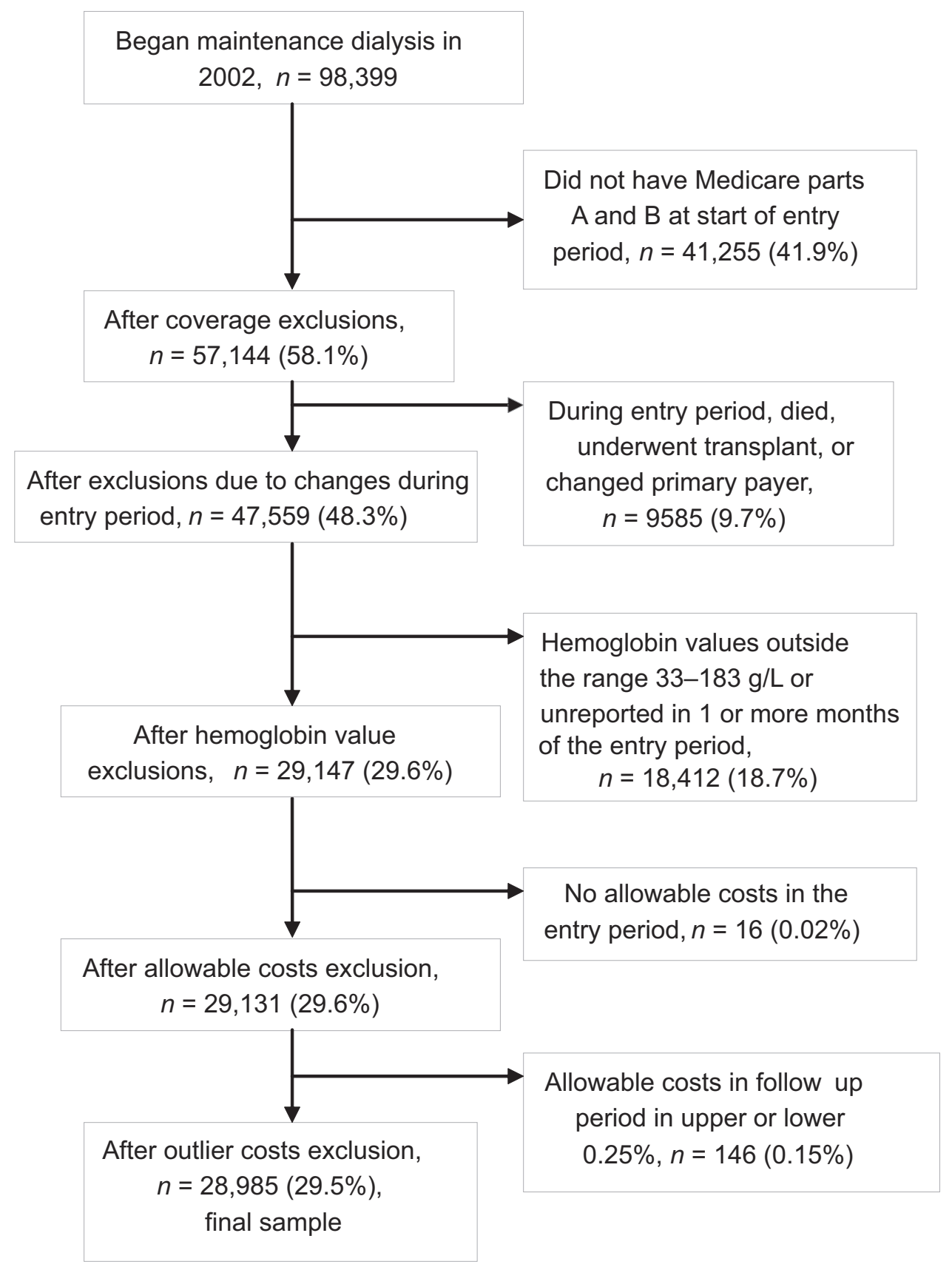

Figure 2 Flow chart for patient selection from the Centers for Medicare and Medicaid Services end-stage renal disease database.

anemia treatment and general severity of illness in the follow-up period, there is no other association between persistent anemia and medical costs, or it is too small to detect. Except $\beta_{1}$, all associations on paths from persistent anemia to medical cost are significant (all $p$-values are $<0.0001$ ). The model was rerun with $\beta_{1}=0$. The model fits the data very well. The R-square for logged PPPM is 0.812; Goodness of Fit Index $=0.976$, Normed Fit Index $=0.91$, Root Mean Square Error Approximation $=0.057$. Table 4 summarizes findings from structural equation models assessing associations between medical costs and persistent anemia. Persistent anemia was associated with future medical costs, an association that persisted when adjustment was made for age, sex, race, ethnicity, diabetes, comorbid conditions, and baseline length of hospital stay. Each additional month with hemoglobin below $110 \mathrm{~g} / \mathrm{L}$ was associated with an $8.9 \%$ cost increment (because the log scale was used for costs, the total percent change has a multiplicative, not an additive relationship, here $1.036 \times 1.051 \approx 1.089$ [95\% confidence 


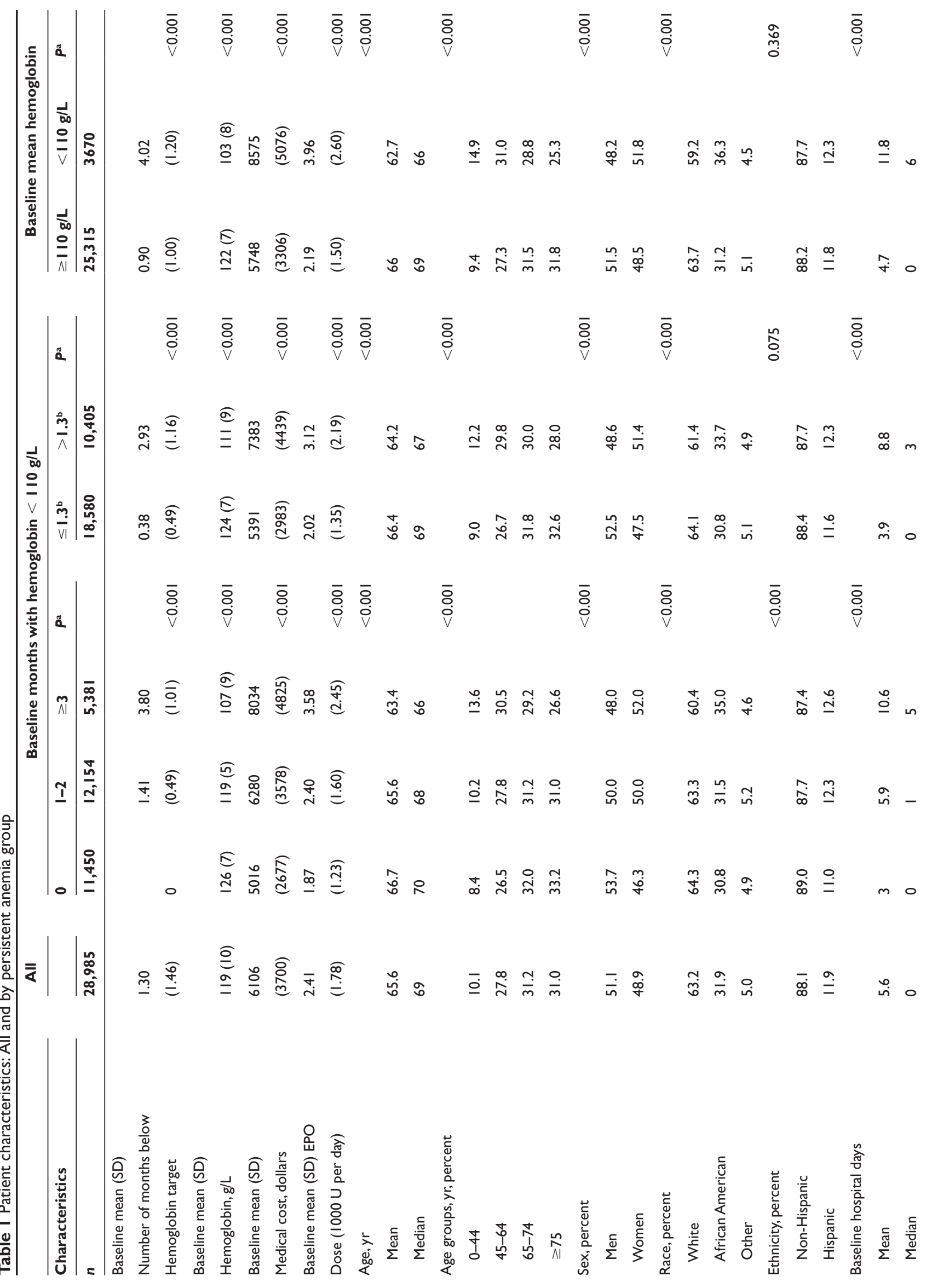




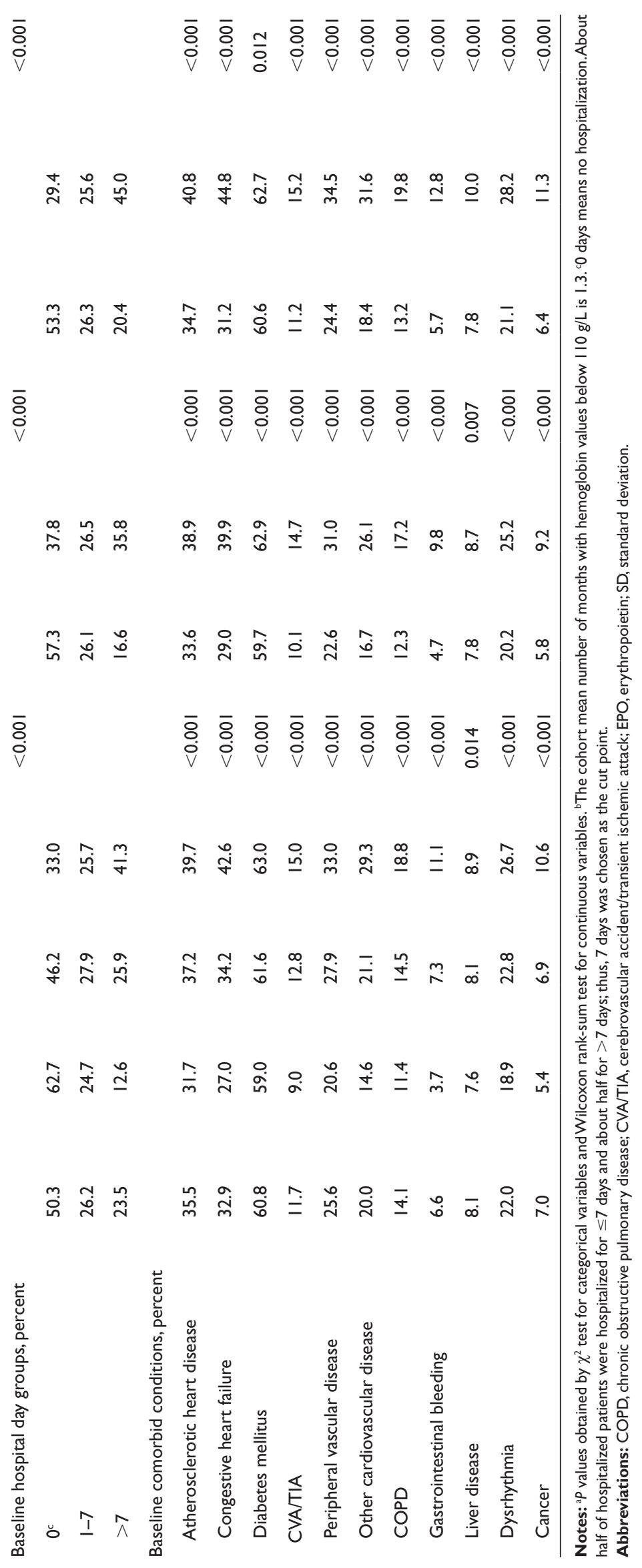


$\underline{\text { Lin et al }}$

Dovepress

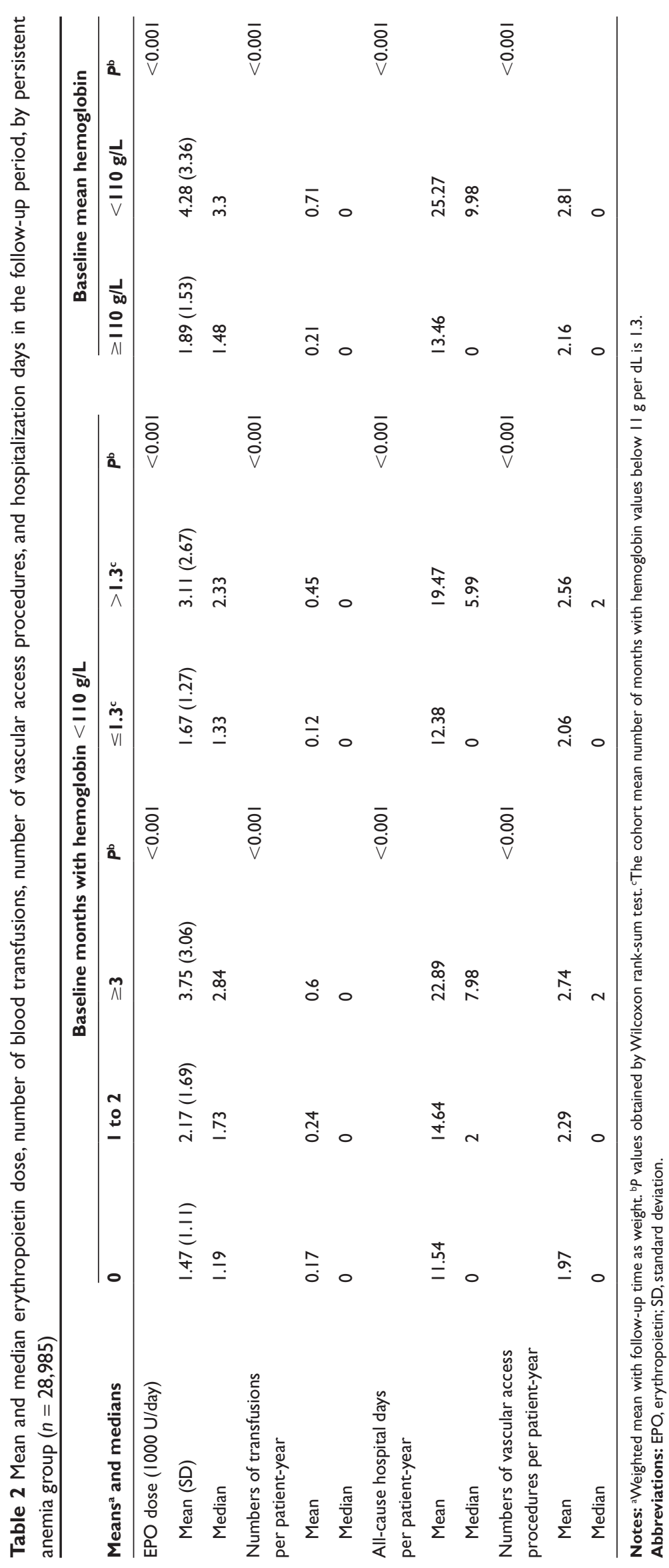

$8 \begin{aligned} & \text { submit your manuscript } \mid \text { www.dovepress.com } \\ & \text { Dovepress }\end{aligned}$

Therapeutics and Clinical Risk Management 2009:5 
Table 3 Mean, median, 25th and 75th percentiles of per patient per month costs in dollars in the follow-up period by persistent anemia group

\begin{tabular}{|c|c|c|c|c|c|c|c|c|c|c|}
\hline \multirow[b]{2}{*}{$\begin{array}{l}\text { Per patient per } \\
\text { month costs, } \$\end{array}$} & \multicolumn{7}{|c|}{ Baseline months with hemoglobin $<110 \mathrm{~g} / \mathrm{L}$} & \multicolumn{3}{|c|}{ Baseline mean hemoglobin } \\
\hline & 0 & I to 2 & $\geq 3$ & $P^{a}$ & $\leq \mathrm{I} .3^{\mathrm{b}}$ & $>1.3^{b}$ & $P^{a}$ & $\geq 110 \mathrm{~g} / \mathrm{L}$ & $<110 \mathrm{~g} / \mathrm{L}$ & $P^{a}$ \\
\hline \multirow[t]{2}{*}{$n$} & 11,450 & 12,154 & 5381 & & 18,580 & 10,405 & & 25,315 & 3670 & \\
\hline & & & & $<0.001$ & & & $<0.001$ & & & $<0.001$ \\
\hline $\operatorname{Mean}^{c}(S D)$ & $546 \mid(494)$ & $6276(554)$ & 8070 (69I) & & $5684(5 \mathrm{I} I)$ & 7349 (643) & & $5958(530)$ & 8562 (737) & \\
\hline Median & $4 \mid 80$ & 4919 & 6802 & & 4376 & 5985 & & 4616 & 7390 & \\
\hline 25th-75th percentiles & $3092-6671$ & $348|-805|$ & $4399-10,998$ & & $3188-7037$ & 3954-9954 & & $3293-7498$ & $4763-11,946$ & \\
\hline
\end{tabular}

Notes: aP values obtained by Wilcoxon rank-sum test. ${ }^{b}$ The cohort mean number of months with hemoglobin values below II0 g/L is 1.3 . ${ }^{\mathrm{c} W e i g h t e d ~ m e a n ~ w i t h ~ f o l l o w-u p ~}$ time as weight.

Abbreviation: SD, standard deviation.

interval $8.2 \%-9.4 \%]$ ). Similarly, each one-unit increase in mean hemoglobin in the entry period was associated with an $11.8 \%$ decrease in medical costs $(95 \%$ confidence interval $10.1 \%-12.4 \%$ ). Medical costs for the $>1.3$-months group were $22.0 \%$ higher than for the $\leq 1.3$-months group. The adjusted difference between the $>$ and $\leq 1.3$-months groups was smaller than the unadjusted difference $(22.0 \%$ vs $29.3 \%)$ because the $>1.3$-months group was more ill, with more comorbid conditions and more hospital days in the entry period (see Table 1).

\section{Discussion}

This study shows that persistent anemia after dialysis therapy initiation is followed by increased medical costs and that the association between persistent anemia and future medical costs was mainly explained by associations with future EPO doses, blood transfusions, hospitalizations, and vascular access procedures in the follow-up period. Hospitalization and vascular access (the indirect costs) appeared to be the more important component of the anemia/cost relationship.

Our finding that persistent anemia is associated with higher medical costs is consistent with previous studies, ${ }^{9-11}$ but our methodology may represent a level of robustness not seen in other observational studies. Structural equation modeling is attractive because it can incorporate complex relationships among the endogenous and exogenous variables. It not only models the association between persistent anemia and medical costs, but also assesses the intermediate factors for

Table 4 Association between persistent anemia and medical costs from structural equation models

\begin{tabular}{|c|c|c|c|}
\hline \multirow[t]{2}{*}{ Association } & \multicolumn{2}{|c|}{ Months with hemoglobin $<110 \mathrm{~g} / \mathrm{L}$} & \multirow[b]{2}{*}{ Mean hemoglobin } \\
\hline & Continuous variable ${ }^{a}$ & $>1.3^{\mathrm{b}}$ & \\
\hline$\gamma_{11}(\mathrm{SE})$ & $0.044(0.00 I)$ & $0.09(0.003)$ & $-0.64(0.002)$ \\
\hline$\gamma_{12}(\mathrm{SE})$ & $0.321(0.016)$ & $0.79(0.043)$ & $-0.474(0.023)$ \\
\hline$\beta_{3}(\mathrm{SE})$ & $0.789(0.048)$ & $0.822(0.065)$ & $0.789(0.049)$ \\
\hline$\beta_{4}(\mathrm{SE})$ & $0.158(0.004)$ & $0.157(0.004)$ & $0.158(0.004)$ \\
\hline \multicolumn{4}{|l|}{ Effect through anemia treatment } \\
\hline Effect at log scale & 0.035 & 0.074 & -0.05 \\
\hline Percentage change at the original scale & 3.6 & 7.7 & -4.9 \\
\hline \multicolumn{4}{|l|}{ Effect through general severity of illness } \\
\hline Effect at log scale & 0.05 & 0.124 & -0.075 \\
\hline Percentage change at the original scale & 5.1 & 13.2 & -7.2 \\
\hline \multicolumn{4}{|l|}{ Total effect $(S E)^{c}$} \\
\hline Effect at log scale & $0.085(0.003)$ & $0.198(0.008)$ & $-0.125(0.004)$ \\
\hline Percentage change at the original scale & $8.9(0.027)$ & $22.0(0.176)$ & $-11.8(0.047)$ \\
\hline
\end{tabular}

Notes: ${ }^{N}$ Number of months with hemoglobin value below $110 \mathrm{~g} / \mathrm{L}$. ${ }^{b}$ The cohort mean number of months with hemoglobin values below $110 \mathrm{~g} / \mathrm{L}$ is $1.3{ }^{\circ}{ }^{\mathrm{C} B o o t s t r a p}$ standard error. Abbreviation: SE, standard error. 
the association. A 6-month follow-up period, much shorter than most other studies, was used because hemoglobin levels change frequently over even short time periods, ${ }^{19}$ and these changes during the follow-up period could affect outcomes if the follow-up time were longer. Assessing the effect of persistent anemia on medical cost would thus be impossible. Our shorter follow-up period avoids this problem.

For incident ESRD patients starting dialysis, minimizing time with hemoglobin values below $110 \mathrm{~g} / \mathrm{L}$ may need to be balanced against the potential for exceeding target hemoglobin levels, which appears to be common. ${ }^{1}$ Although the higher hemoglobin levels, like the levels below $110 \mathrm{~g} / \mathrm{L}$, may be transient, safety concerns related to higher targeted hemoglobin levels were reported in the Normal Hematocrit Study ${ }^{20}$ and the Correction of Hemoglobin and Outcomes in Renal Insufficiency (CHOIR) study. ${ }^{21}$ Adverse morbidity and mortality outcomes occurred in the higher hemoglobin target group, a finding that should be carefully considered. Conversely, the lower hemoglobin levels are also of concern because they also appear to be linked to morbidity and costs. Time within the target hemoglobin range of 110 to $120 \mathrm{~g} / \mathrm{L}$ may be the best measure of successful anemia treatment.

Because more than $90 \%$ of patients had at most three months with hemoglobin values below $110 \mathrm{~g} / \mathrm{dL}$, the effect of patients with more than three months on the parameter estimate was weak. Therefore, interpretation of results should focus on patients with hemoglobin values below $110 \mathrm{~g} / \mathrm{L}$ for three months or less. Similarly, interpretation of the results should focus on patients with mean hemoglobin values between 100 and $130 \mathrm{~g} / \mathrm{L}$, because mean hemoglobin values for most patients fell in this range. It should be noted that achieved patient hemoglobin levels are the result of the target hemoglobin level, treatment, and patient health status. The target range was likely $110-130 \mathrm{~g} / \mathrm{L}$ for most of patients, because that was the KDOQI recommended target range during the study period. The results of this study are consistent with results in the Normal Hematocrit Study ${ }^{20}$ in the sense that for each target group, those with higher hematocrit had better outcomes.

The limitations of this study are related to its retrospective design and its reliance on administrative claims. Though the results are adjusted for numerous baseline patient factors, residual confounding remains possible and likely. Also, the results are adjusted for patient comorbid conditions, but condition severity, which might be associated with both persistent anemia and medical costs, is not available in the data. Survival for nine months (three months before the entry period and six months during the entry period), primary coverage by Medicare Parts A and B, and six months of hemoglobin reports in the entry period were study entry criteria, and the findings may not be generalizable to all incident patients numerically; however, the pattern of associations should be the same.

\section{Disclosure}

This study was supported by a research contract from Roche Laboratories, Nutley, New Jersey, USA. The contract provides for the authors to have final determination of manuscript content. Jiannong Liu and Haifeng Guo have no conflict of interest with its subject matter. David T Gilbertson, Robert N Foley, and Allan J Collins have received consulting fees from Roche. The authors thank Chronic Disease Research Group colleagues Shane Nygaard, BA, for manuscript preparation and Nan Booth, MSW, MPH, for manuscript editing.

\section{References}

1. US Renal Data System. USRDS 2006 Annual Data Report. Bethesda, MD: National Institutes of Health, National Institute of Diabetes and Digestive and Kidney Diseases; 2006.

2. NKF-DOQI clinical practice guidelines for the treatment of anemia of chronic renal failure. National Kidney Foundation-Dialysis Outcomes Quality Initiative. Am J Kidney Dis. 1997;30(4 Suppl 3):S192-S240.

3. National Kidney Foundation. K/DOQI Clinical Practice Guidelines and Clinical Practice Recommendations for Anemia in Chronic Kidney Disease: 2007 Update of Hemoglobin Target. Am J Kidney Dis. 2007;50:471-530.

4. Robertson HT, Haley NR, Guthrie M, Cardenas D, Eschbach JW, Adamson JW. Recombinant erythropoietin improves exercise capacity in anemic hemodialysis patients. Am J Kidney Dis. 1990;15:325-332.

5. Pickett JL, Theberge DC, Brown WS, Schweitzer SU, Nissenson AR. Normalizing hematocrit in dialysis patients improves brain function. Am J Kidney Dis. 1999;33(6):1122-1130.

6. Foley RN, Parfrey PS, Harnett JD, Kent GM, Murray DC, Barre PE. The impact of anemia on cardiomyopathy, morbidity, and mortality in end-stage renal disease. Am J Kidney Dis. 1996;28:53-61.

7. Harris DCH, Lawrence S, Champion JR. Low dose erythropoietin in maintenance hemodialysis patients: improvement in quality of life and reduction in true cost of hemodialysis. N Z Med J. 1991;21:693-700.

8. Stevens ME, Summerfield GP, Hall AA. Cost benefits of low dose subcutaneous erythropoietin in patients with anemia of end stage renal disease. Br Med J. 1992;304:474-477.

9. Powe NR, Griffiths RI, Watson AJ, et al. Effect of recombinant erythropoietin on hospital admissions, readmissions, length of stay, and costs of dialysis patients. J Am Soc Nephrol. 1994;4(7):1455-1465.

10. Collins AJ, Li S, Ebben J, Ma JZ, Manning W. Hematocrit levels and associated Medicare expenditures. Am J Kidney Dis. 2000;36(2): 282-293.

11. Collins AJ, Li S, St. Peter WL, et al. Death, hospitalization, and economic associations among incident hemodialysis patients with hematocrit values of $36 \%$ to $39 \%$. J Am Soc Nephrol. 2001;12:2465-2473.

12. Ishani A, Guo H, Gilbertson DT, et al. Time to target haemoglobin concentration $(11 \mathrm{~g} / \mathrm{dl})$-risk of hospitalization and mortality among incident dialysis patients. Nephrol Dial Transplant. 2007;22:2247-2255.

13. Hebert PL, Geiss LS, Tierney EF, Engelgau MM, Yawn BP, McBean AM. Identifying persons with diabetes using Medicare claims data. Am J Med Qual. 1999;14(6):270-277.

14. Kline RB. Principles and practice of Structural Equation Modeling. New York, NY: The Guilford Press; 1998. 
15. Bartholomew DJ, Knott M. Latent Variable Models and Factor Analysis. 2nd ed. New York, NY: Oxford University Press; 1999.

16. Batista-Foguet JM, Coenders G, Ferragud MA. Using structural equation models to evaluate the magnitude of measurement error in blood pressure. Stat Med. 2001;20(15):2351-2368.

17. Donaldson GW. General linear contrasts on latent variable means: structural equation hypothesis tests for multivariate clinical trials. Stat Med. 2003;22(18):2893-2917.

18. Lee SY, Song XY. Bayesian analysis of structural equation models with dichotomous variables. Stat Med. 2003;22(19):3073-3088.
19. Ebben JP, Gilbertson DT, Foley RN, Collins AJ. Hemoglobin level variability: associations with comorbidity, intercurrent events, and hospitalizations. Clin J Am Soc Nephrol. 2006;1(6):1205-1210.

20. Besarab A, Bolton WK, Browne JK, et al. The effects of normal as compared with low hematocrit values in patients with cardiac disease who are receiving hemodialysis and epoetin. $N$ Engl $J$ Med. 1998;339(9):584-590.

21. Singh AK, Szczech L, Tang KL, et al. Correction of anemia with epoetin alfa in chronic kidney disease. $N$ Engl J Med. 2006;355(20): 2085-2098. 


\section{Appendix}

International Classification of Diseases, Ninth Revision, Clinical Modification (ICD-9-CM) Codes, Current Procedural Terminology (CPT) Codes, and V-Codes Used to Define Comorbid Conditions and Vascular Access

\begin{tabular}{lll}
\hline Condition/Access & ICD-9-CM Code/CPT Code & V-code \\
\hline Atherosclerotic heart disease & $410 . x x-4 I 4 . x x$ & V45.8I; V45.82 \\
Congestive heart failure & $398.9 I ; 422 . x x ; 425 . x x ; 428 . x x ; 402 . x I ; 404 . x I ; 404 . x 3$ & V42.I \\
Cerebrovascular accident/transient ischemic attack & $430 . x x-438 . x x$ & $440 . x x-444 . x x ; 447 . x x ; 45 I . x x-453 . x x ; 557 . x x$ \\
Peripheral vascular disease & $420 . x x-42 I . x x ; 423 . x x-424 . x x ; 429 . x x ; 785.0-785.3$ & V42.2; V43.3 \\
Cardiac (other) & $49 I-494 ; 496 . x x ; 510 . x x$ \\
Chronic obstructive pulmonary disease & $456.0-456.2 ; 530.7 ; 53 I-534 ; 569.84 ; 569.85 ; 578$ \\
Gastrointestinal bleeding & $570 . x x ; 57 I . x x ; 572.1 ; 572.4 ; 573.1-573.3$ & \\
Liver disease & $426 . x x-427 . x x$ & V42.7 \\
Dysrhythmia & I40.xx-172.xx; I74.xx-208.xx; 230.xx-23I.xx; 233.xx-234.xx \\
Cancer & $250 . x x ; 357.2 ; 362.0 x ; 366.4 I$ \\
Diabetes & $C P T$ code 36800 alone; CPT codes 36488, 36489, 36490, \\
Vascular access & $3649 I, 36533$ associated with diagnosis codes 250.xx, 403.xx, \\
& $593 . x x, V 56 . x, 996.1,996.62,996.73, V 45 . I$, or 580.xx-589.xx \\
\hline
\end{tabular}

\section{Publish your work in this journal}

Therapeutics and Clinical Risk Management is an international, peerreviewed journal of clinical therapeutics and risk management, focusing on concise rapid reporting of clinical studies in all therapeutic areas, outcomes, safety, and programs for the effective, safe, and sustained use of medicines. This journal is indexed on PubMed Central, CAS,
EMBase, Scopus and the Elsevier Bibliographic databases. The manuscript management system is completely online and includes a very quick and fair peer-review system, which is all easy to use. Visit http://www.dovepress.com/testimonials.php to read real quotes from published authors. 